\title{
Pathogenicity of the MAGE family (Review)
}

\author{
SANYAN LI ${ }^{1 *}, \mathrm{XIANG} \mathrm{SHI}^{1 *}, \mathrm{JINGPING} \mathrm{LI}^{2}$ and XIANRONG ZHOU ${ }^{1}$ \\ Departments of ${ }^{1}$ Pathology and ${ }^{2}$ Respiratory Medicine, Qianjiang Central Hospital, Qianjiang, Hubei 433100, P.R. China
}

Received July 13, 2021; Accepted October 7, 2021

DOI: $10.3892 / 01.2021 .13105$

\begin{abstract}
The melanoma antigen gene (MAGE) protein family is a group of highly conserved proteins that share a common homology domain. Under normal circumstances, numerous MAGE proteins are only expressed in reproduction-related tissues; however, abnormal expression levels are observed in a variety of tumor tissues. The MAGE family consists of type I and II proteins, several of which are cancer-testis antigens that are highly expressed in cancer and serve a critical role in tumorigenesis. Therefore, this review will use the relationship between MAGEs and tumors as a starting point, focusing on the latest developments regarding the function of MAGEs as oncogenes, and preliminarily reveal their possible mechanisms.
\end{abstract}

\section{Contents}

1. Introduction

2. MAGE family and its encoded proteins

3. Relationship between the MAGE family and ubiquitination and disease

4. Mechanism of MAGE and tumorigenesis

5. Relationship between MAGE and tumor prognosis and invasion

6. Summary and outlook

Correspondence to: Professor Xianrong Zhou, Department of Pathology, Qianjiang Central Hospital, 22 Zhang Hua Street, Qianjiang, Hubei 433100, P.R. China

E-mail: zhouxianrong08@126.com

Professor Jingping Li, Department of Respiratory Medicine, Qianjiang Central Hospital, 22 Zhang Hua Street, Qianjiang, Hubei 433100, P.R. China

E-mail: lijingping@126.com

*Contributed equally

Key words: melanoma antigen gene, ubiquitination, tumorigenesis, pathogenicity

\section{Introduction}

The high incidence of tumors worldwide has become a threat to human health, and thus, novel and effective treatments need to be identified urgently. Due to its high specificity and low side effects, immunotherapy has unique advantages in preventing tumor recurrence and metastasis, and has gradually attracted attention (1). Actively screening and identifying antigens with high specificity in tumors is the first prerequisite for immunotherapy, and the melanoma antigen gene (MAGE) family is one of the antigen targets of potential tumor therapy that has been paid attention to.

MAGE, specifically type I MAGE, is an important member of the cancer testis antigen (CTA) family (2). The antigen mainly has the following characteristics (3): i) Expressed only in gamete developmental system tissues and tumor tissues; ii) its coding genes are mainly located on the $\mathrm{X}$ chromosome; iii) abnormal expression in tumor tissues, with different expression rates in tumor tissues from different sources; iv) its expression is related to tumor metastasis and deterioration; and v) hypomethylation and/or histone deacetylase inhibitors can activate it in vitro.

\section{MAGE family and its encoded proteins}

MAGE family members have attracted increasing attention as biomarkers in cancer and as immunotherapy targets. In total, $>40$ human proteins are considered CTAs, and these are mainly locally expressed in testis tissues, and partly expressed in ovarian and placental tissues (4). MAGE proteins are normal tissue antigens that exist in testicular cells, serve an important role in the early stages of spermatogenesis and are abnormally highly expressed in cancer types that may be immunogenic (5). MAGE-related antigens have a tumor-specific related expression pattern, which can form tumor-specific antigen polypeptides that can be recognized by immune cells and induce immune responses, so they are often used as molecular targets for tumor diagnosis and immunotherapy $(6,7)$.

MAGE genes are conserved in all eukaryotes, the average conservation rate in all human MAGEs reaches $46 \%$ and the number of gene copies in mammals is rapidly expanding (8). According to their tissue expression patterns, the members of the human MAGE family can be roughly divided into two categories (9): Type I MAGEs and type II MAGEs (Fig. 1). Type I MAGEs are regarded as CTAs, and these include the sub-families of MAGE-A, MAGE-B and MAGE-C clustered on the $\mathrm{X}$ chromosome $(5,10)$. Type I MAGEs are highly 
expressed cancer antigens, and they serve an important role in tumorigenesis and cancer cell survival (9). Therefore, they are rarely expressed in normal adult tissues, but are highly expressed in various cancer types, including melanoma and breast cancer, while other types of cancer, such as prostate cancer, lung adenocarcinoma, esophageal squamous cell carcinoma, stomach cancer, bladder cancer, ovarian cancer, hepatocellular carcinoma and brain cancer, may also express high levels of MAGE (11-15). The type II MAGE family mainly includes the MAGE-D, MAGE-E, MAG-F, MAG-G, MAGE-H and MAGE-L subfamilies and Necdin, which are expressed in numerous tissues of the human body and are not limited to the X chromosome (10). Both type I and II MAGEs contain a MAGE homology domain (MHD) of $\sim 170$ amino acids (16). By studying its structure, it has been revealed that MHD is composed of a series of double-winged helix motifs, and part of the ubiquitination and methylation functions of MAGE are inseparable from the special structure of MHD (17).

The MAGE family has specific functions in normal development and tumor progression. Most of the type I MAGEs are only normally expressed in the testis or placenta, and their restricted expression characteristics suggest that they may serve a role in germ cell development (18). Numerous studies have consistently demonstrated that the MAGE-A family may serve an important role in spermatogenesis and embryonic development $(15,19)$. In addition, MAGE-A protein has been detected by immunohistochemistry in the early development of the spinal cord and brain stem of the central nervous system and peripheral nerves (20), which indicates that MAGE-A protein is also involved in the development of neurons $(16,21)$. A study also found that MAGE-B4 was highly expressed during the germ cell differentiation process before meiosis, indicating that the MAGE protein may also serve a role in oocyte development (22). Type II MAGEs are highly expressed in the brain and participate in various neuromodulation processes. These MAGE proteins may serve an important role in differentiation and neurodevelopment, and thus, their loss of function will lead to a series of cognitive behavioral and developmental defects (23). The MAGE gene can encode part of an antigen peptide to activate immune cells to kill tumor cells and become cancer biomarkers and immunotherapy targets (24). However, further studies have demonstrated that MAGEs can not only drive tumorigenesis, but also participate in the regulation of a variety of cell and developmental processes.

\section{Relationship between the MAGE family and ubiquitination and disease}

Ubiquitination refers to a process in which ubiquitin molecules classify proteins in cells under the action of a series of special enzymes, select target protein molecules from them and specifically modify the target protein. Ubiquitination is involved in the regulation of almost all life activities, such as the cell cycle, proliferation, apoptosis, differentiation, metastasis, gene expression, transcription regulation, signal transmission, damage repair, inflammation and immunity (25). Ubiquitination modification involves a series of reactions with ubiquitin-activating enzyme E1, ubiquitin conjugating enzyme E2 and ubiquitin ligase E3: First, enzyme E1 adheres to the Cys residue at the tail of the ubiquitin molecule and is activated when ATP is supplied. Next, E1 transfers the activated ubiquitin molecule to E2 enzyme, and then, E2 enzyme and some different types of E3 enzymes recognize the target protein together and modify it for ubiquitination. According to the relative ratio of E3 to the target protein, the target protein can be modified by monoubiquitination and polyubiquitination. The appearance of the E3 enzyme acts like a clip, and the target protein is connected in the middle gap. The left domain of the enzyme determines the specific recognition of the target protein, and the right domain locates the E2 enzyme to transfer ubiquitin molecules. As a result of protein ubiquitination, the labeled protein is broken down by proteases into smaller peptides, amino acids and ubiquitin that can be reused (26-28). In terms of the previously identified interactions between several MAGE proteins and RING domain proteins, it was found that they will form complexes, such as MAGE-A2/C2-triple motif (TRIM)28, MAGE-B18-ligand of numb-protein X and MAGE-G1-non-structural maintenance of chromosomes element 1 (NSE1) complexes (29). The RING domain is a cysteine-rich domain, which usually forms a coordinated cross-scaffold structure with two zinc ions (30). Experiments have demonstrated that RING domain proteins are a large family of E3 ubiquitin ligases, which can be combined with E2 ubiquitin conjugating enzymes and positioned on the substrate for ubiquitination (31). The subfamily of E3 ubiquitin ligases change the relative orientation of the two-winged helix motifs through the binding of the MHD to the specific E3 RING ubiquitin ligase (11). MAGEs and RING proteins bind to form an important structure of the MAGE-RING complex known as the MAGE-G1-NSE1 complex. Based on this structure, the MAGE protein can regulate the E3 of its homologous RING partner in vivo and in vitro via ubiquitin ligase activity (32). MAGEs can regulate the ubiquitination of proteins by regulating the activity of their homologous E3 ligase, which includes enhancing general ligase activity, binding and specifying new substrates for ubiquitination by E3 ligase complexes, and changing the subcellular localization of E3 ligase to produce specific biological functions $(33,34)$. Therefore, the abnormal expression of MAGEs in tumor cells can promote tumorigenesis via ubiquitination and other possible changes, leading to changes in cell processes and signaling pathways.

MAGE proteins have a biochemical effect involving binding to and enhancing the activity of E3 RING ubiquitin ligase, and related proteomic analysis has revealed that MAGE-L2, a type II MAGE, can specifically bind to TRIM27 E3 RING ubiquitin ligase (34). TRIM27 belongs to one of the largest families of E3 RING ubiquitin ligases and is referred to as the TRIM protein. TRIM27 was originally identified and named Ret finger protein, as it is a gene that has a translocation mutation with the Ret tyrosine kinase receptor in thyroid cancer (35). Additionally, subsequent studies revealed that it was also involved in the regulation of several biological transformation processes, including transcriptional regulation, $\mathrm{NF}-\kappa \mathrm{B}$ signal transduction and the maintenance of $\mathrm{CD} 4^{+} \mathrm{T}-\mathrm{cell}$ homeostasis, and that, as an oncogene, it participates in regulating the occurrence and development of tumors $(7,36,37)$. MAGE-L2 and TRIM27 co-localize on the cytoplasmic structure of retromer-positive endosomes (38). Furthermore, 


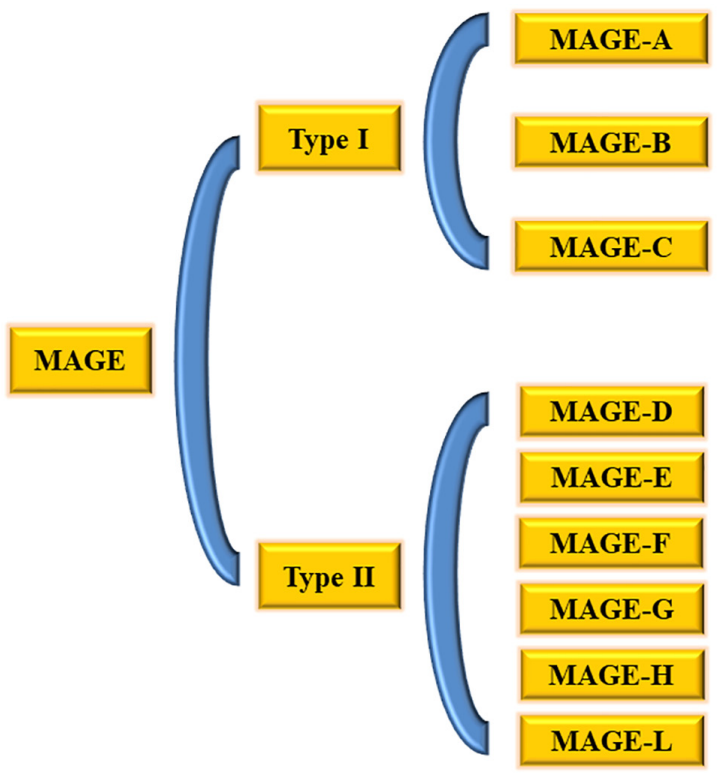

Figure 1. Main members of the MAGE family. The MAGE family is divided into type I and II. Type I is only expressed in testicular and placental tissues in normal tissues, but it is expressed at different levels in numerous types of tumors. Type II can be expressed in some normal tissues, including testicular and placental tissues, and it can be expressed in tumors. MAGE, melanoma antigen gene.

the localization of TRIM27 is regulated by the protein kinase C, JNK and RAS signaling pathways (39).

In addition to the important connection between MAGE-L2 and TRIM27 in E3 RING ubiquitination, MAGE-L2 also serves an important role in reverse transport between cells (38). Studies have revealed that genes required for reverse transport are often present in a high-copy state in melanoma, which facilitates the transport of related proteins, and thus helps mediate tumorigenesis $(40,41)$. There are also reports that the downregulation and mutation of reverse transport-related molecules may be involved in the occurrence of Alzheimer's disease (42). Downregulated MAGE-L2 has been detected in the hippocampus of patients with early Alzheimer's disease (42). Reverse transport is an indispensable way for numerous microbial toxins and certain viruses to enter cells. In fact, the inhibitory effect of TRIM27 can prevent the transport of cholera toxin (43).

\section{Mechanism of MAGE and tumorigenesis}

MAGE proteins directly bind to RING domain proteins and act as a substrate scaffold for the RING domain proteins, thereby regulating their ubiquitin ligase activity (11). In particular, it has been reported that MAGE-A2, MAGE-A3, MAGE-A6 and MAGE-C2 binding to TRIM28, also known as Krüppel-associated box (KRAB)-associated protein 1 (KAP1), transcriptional intermediary factor $1 \beta$ or Krip125, induces the degradation of the tumor suppressor p53 $(44,45)$. In the presence of wild-type p53, knockdown of the MAGE-A gene appears to increase the recruitment of p53 to the target promoter and increases the mRNA levels of the p53 transcription target (46). Type I MAGE combined with KAP1 induces the polyubiquitination and degradation of the substrate zinc finger protein 382 (ZNF382) (47). ZNF382 is a member of the KRAB domain zinc finger transcription factor (KZNF) family and is associated with apoptosis and tumor suppression (48). KZNFs bind to the KAP1 protein and direct KAP1 to a specific DNA sequence, and then KZNF inhibits gene expression by inducing local heterochromatin characterized by histone 3 lysine 9 trimethylation (44). MAGE-C2 may also increase the phosphorylation of TRIM28/KAP1 and improve DNA repair after double-strand breaks by enhancing the formation of complexes between TRIM28/KAP1 and ATM serine/threonine kinase (49). The combination of MAGE and KAP1 induces the degradation of ZNF382, resulting in a decrease in the combination of KAP1 and DNA binding inhibitor 1 (ID1) and an increase in the expression of the oncogene ID1 (44). Therefore, it appears that the MAGE family binds to the RING domain protein KAP1 through specific upregulation, triggering the ubiquitination and degradation of a variety of tumor suppressor factors, such as p53, AMP-activated protein kinase (AMPK) $\alpha 1$ and ZNF382 (44), thereby promoting tumor occurrence and invasive growth (Fig. 2). Therefore, the identification of novel small molecules that inhibit the protein-protein interaction between MAGE and KAP1 may be a potential strategy for the treatment of cancer with upregulated MAGE expression (50).

However, the relevance of MAGE-A in tumors is not limited to the scope of regulating p53 function. In numerous tumor types, the expression of MAGE-A3 or MAGE-A6 has nothing to do with p53 mutation status (51). As aforementioned, the MAGE-A3-TRIM28 and MAGE-A6-TRIM28 ligase complexes can ubiquitinate the $\alpha$ catalytic subunit of the tumor suppressor AMPK (PRKAA1), which mainly functions as a cell energy sensor and regulator $(52,53)$. This leads to degradation of AMPK and decreases the expression level of total AMPK protein in tumors. In the early stage of tumorigenesis, the deletion of the AMPK gene promotes tumor induction (54). Clinicopathological data have demonstrated that insufficient AMPK activity in tumor tissues is considered to be one of the causes of malignant tumors (54). In addition, the downregulation of AMPK by MAGE-A3 and MAGE-A6 leads to a decrease in autophagy levels and an upregulation of mTOR signals, which may provide the best conditions for the early formation and growth of tumors $(55,56)$. When AMPK agonists are used, they can decrease the anchorage-independent growth mediated by MAGE-A6 in vitro. In addition, due to the methylation of $\mathrm{CpG}$ islands in the promoter region, type I MAGEs are usually not expressed in somatic cells (57). When the type I MAGE promoter is demethylated, it can downregulate the activity of KIT proto-oncogene, receptor tyrosine kinase (KIT) tyrosine kinase and the upstream regulator fibroblast growth factor receptor 2 (FGFR2)-IIIb of MAGE-A3/6. Knockdown of fibronectin also leads to increased MAGE-A3 expression $(58,59)$. Fibronectin signal transduction via integrin receptors, FGFR2 signal transduction and c-KIT pathways all involve PI3K/Akt and Ras pathways, which suggests that these pathways may be the key to understanding how to activate type I MAGE in cancer cells (60).

MAGE-A11 is a relatively unique subtype of type I MAGE, and it is involved in the regulation of hormone signaling in prostate cancer $(61,62)$. The binding of MAGE-A11 to the $\mathrm{N}$-terminal FXXLF motif of the androgen receptor (AR) helps 


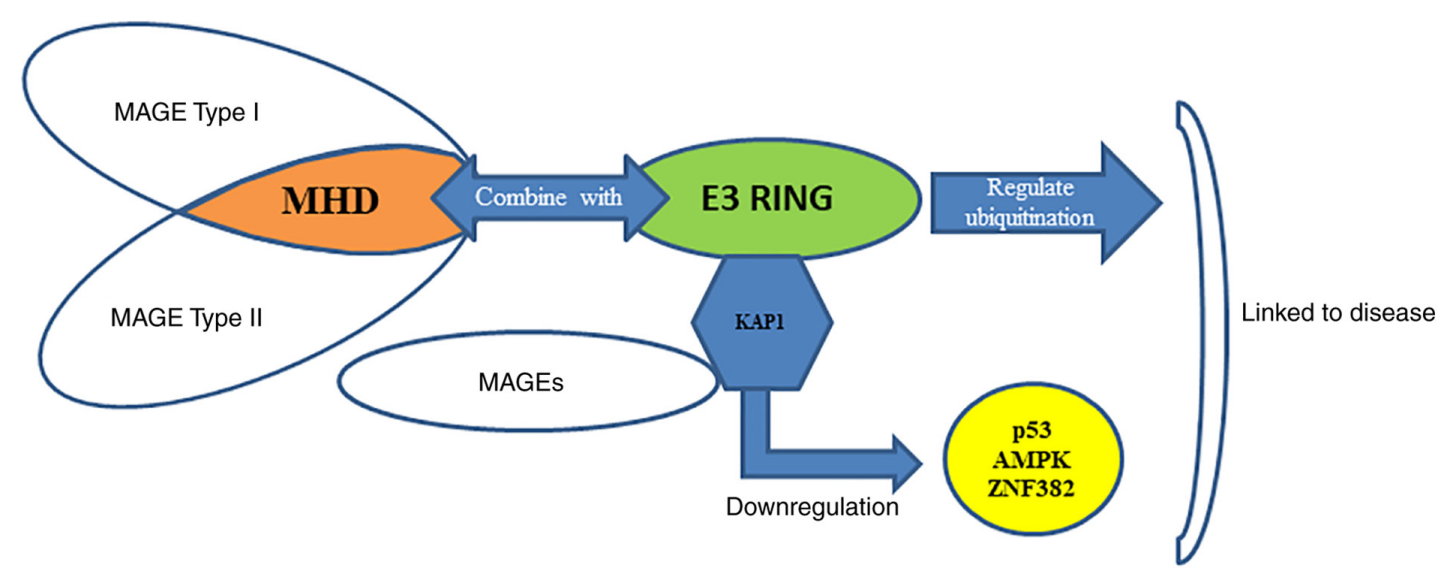

Figure 2. Binding of the MHD of type I and II MAGEs to a specific E3-RING ubiquitin ligase regulates protein ubiquitination. The MAGE family is upregulated and bound to the RING domain protein KAP1, triggering the ubiquitination and degradation of a variety of tumor suppressor factors, and ultimately leading to the occurrence of diseases. MAGE, melanoma antigen gene; MHD, MAGE homology domain; KAP1, Krüppel-associated box-associated protein 1; AMPK, AMP-activated protein kinase; ZNF382, zinc finger protein 382.

the SRC/p160 co-activator to bind and form a complex with the $\mathrm{AR}$ of prostate cancer by regulating the interaction between AR domains (62). To enhance AR transcriptional activity, increased MAGE-11 expression promotes the progression of prostate cancer by enhancing the growth of AR-dependent tumors (63). Further studies have demonstrated that the interaction between AR and MAGE-A11 is mediated by the combination of the FXXLF motif at the AR NH2-terminal and the highly conserved MAGE-A11 F-box (residues 329-369) in the MHD (64,65). Additionally, this interaction is regulated by serum-stimulated phosphorylation of mitogen-activated protein kinase of MAGE-A11 Ser-174 (66). In addition, epidermal growth factor-mediated phosphorylation and ubiquitination of MAGE-A11 enhances the transcriptional activity of AR (64). MAGE-A11 also acts as a transcriptional co-regulator by interacting with progesterone receptor and steroid receptor-related EP300 and EP160 coactivators (67), and by interacting with p107 and E2F transcription factor 1 transcription factors, which are important in the cell cycle. MAGE-A11 is closely related to the cell cycle. Among several factors that affect tumor progression, cell cycle intervention is an important step (68). In addition to regulating hormone signaling, MAGE-A11 may also mediate tumor survival by stabilizing hypoxia-inducible factor- $1 \alpha$ levels, possibly by binding to and inhibiting proline 4 (69). In terms of the epigenetic regulation of MAGE-A11, DNA methylation is involved in the specific regulation of MAGE-A11-1 nucleosome occupancy (57), methylation of a single Ets site near the transcription start site and -1 nucleosome. The occupancy rate of MAGE-A11 is related, and it strongly inhibits the activity of the MAGE-A11 promoter by itself (63). Therefore, DNA methylation regulates the nucleosome occupancy of MAGE-A11 (63), which cooperates with sequence-specific transcription factors to regulate MAGE-A11 gene expression. In epithelial ovarian cancer, MAGE-A11 expression is also related to DNA hypomethylation at its transcription start site (70). The demethylating agent decitabine can decrease the methylation level of the MAGE-A11 promoter, and its promoter activity is partly determined by the transcription factor Sp1 (71). The Sp1 inhibitor Mithramycin A may cause a dose-dependent decrease in
MAGE-A11 promoter activity and endogenous MAGE-A11 expression (71). In summary, DNA methylation serves an important role in MAGE-A11 gene silencing, which is also closely associated with the biological behavior of tumors and is an important direction for researchers.

In addition to having oncogene functions, MAGEs also have the characteristics of stem cell-like side populations of certain tumors. Compared with that in the main population, MAGE-A3 is expressed at higher levels in the tumor stem cell-like side population of bladder cancer (72). In addition, MAGE-A2, MAGE-A3, MAGE-A4, MAGE-A6, MAGE-A12 and MAGE-B2 are highly enriched in stem cell-like side populations of various tumor cell lines, such as liver and lung cancer cells and melanoma cells (73,74). Furthermore, analysis of the maturation stage of B cells revealed that MAGE-C1 is expressed at a high frequency in $\mathrm{CD}_{3} 4^{+}$stem cells and immature $\mathrm{B}$ cells $\left(\mathrm{CD}_{10}{ }^{+}\right.$or $\left.\mathrm{CD} 19^{+}\right)$, suggesting that MAGE-C1 may be related to the initial cell population of the disease (75). Furthermore, MAGE-C1 is associated with a shortened recurrence cycle and a decrease in overall survival after allogeneic stem cell transplantation (76-78).

\section{Relationship between MAGE and tumor prognosis and invasion}

Extensive research on MAGE expression in various cancer types has demonstrated its predictive association with a poor clinical prognosis. For example, in non-small cell lung cancer, high expression levels of MAGE-A3 and MAGE-A9 are associated with a decrease in patient survival rate $(63,77)$. In breast cancer, high expression levels of MAGE-A3, MAGE-A6 and MAGE-C2 are associated with a high probability of negative estrogen receptor or progesterone receptor status, and increased malignant degree of the tumor (79). In ovarian cancer, the expression of MAGE-A1, MAGE-A9 and MAGE-A10 is associated with a poor prognosis $(80,81)$. In addition, high expression levels of MAGEs are also related to the increase in the recurrence rate after treatment. In gastric cancer, the expression levels of MAGE-A1-6 in the peritoneal lavage fluid after tumor resection are associated with a decrease in 
disease-free survival rate (82). In hepatocellular carcinoma, MAGE-A9 expression is closely associated with a decrease in the disease-free survival rate, and the grade, metastasis, portal vein invasion and overall survival rate of advanced tumors are closely related (83).

MAGEs are not only associated with a poor clinical prognosis, but, as indicated by previous studies, can act as drivers of tumorigenesis. High expression of MAGEs in a variety of tumors, including breast, lung and colon cancer, may increase their viability and invasiveness. In melanoma and multiple myeloma, MAGE-As or MAGE-Cs are involved in promoting survival and invasion $(84,85)$. The expression of MAGE-A3 and MAGE-C2 in cancer cell lines has been demonstrated to increase the invasion potential in vitro (86). In addition, MAGE-A3 and MAGE-A6 promote the transformation of fibroblasts and increase the proliferation of cancer cells, and MAGE-A6 promotes the anchorage-independent growth of normal diploid colon epithelial cells (13). Overexpression of MAGE-A3 is associated with an increased probability of tumor growth and metastasis to the lungs of human thyroid cancer cells, while knockdown of MAGE-C delays the formation of metastatic melanoma in the body (87). This conclusion has been further verified in a syngeneic mouse tumor model.

\section{Summary and outlook}

In conclusion, the MAGE family is overexpressed in various tumors and some diseases. MAGEs can promote tumor progression through various mechanisms, and eventually lead to more aggressive and recurring possibilities for some tumors. Therefore, MAGEs have also become potential targets for cancer treatment. More research on the mechanism of MAGE function in cancer will promote the development of its targeted therapy. In short, as the majority of researchers conduct more and more in-depth studies on the MAGE family, its potential pathogenic mechanism will gradually become clear, laying the foundation for the treatment of related diseases.

\section{Acknowledgements}

Not applicable.

\section{Funding}

No funding was received.

\section{Availability of data and materials}

Not applicable.

\section{Authors' contributions}

$\mathrm{XZ}$ and JL designed the theme of the review. SL and XS retrieved the relevant literature and wrote and reviewed the article. All authors have read and approved the final manuscript. Data authentication is not applicable.

\section{Ethics approval and consent to participate}

Not applicable.

\section{Patient consent for publication}

Not applicable.

\section{Competing interests}

The authors declare that they have no competing interests.

\section{References}

1. Tan S, Li D and Zhu X: Cancer immunotherapy: Pros, cons and beyond. Biomed Pharmacother 124: 109821, 2020.

2. Yakirevich E, Sabo E, Lavie O, Mazareb S, Spagnoli GC and Resnick MB: Expression of the MAGE-A4 and NY-ESO-1 cancer-testis antigens in serous ovarian neoplasms. Clin Cancer Res 9: 6453-6460, 2003.

3. Scanlan MJ, Simpson AJ and Old LJ: The cancer/testis genes: Review, standardization, and commentary. Cancer Immun 4: 1, 2004.

4. Liu Y, Wen L, Ma L, Kang Y, Liu KY, Huang XJ, Ruan GR and Lu J: MAGE genes: Prognostic indicators in AL amyloidosis patients. J Cell Mol Med 23: 5672-5678, 2019.

5. Simpson AJ, Caballero OL, Jungbluth A, Chen YT and Old LJ: Cancer/testis antigens, gametogenesis and cancer. Nat Rev Cancer 5: 615-625, 2005.

6. Sanderson JP, Crowley DJ, Wiedermann GE, Quinn LL, Crossland KL, Tunbridge HM, Cornforth TV, Barnes CS, Ahmed T, Howe K, et al: Preclinical evaluation of an affinity-enhanced MAGE-A4-specific T-cell receptor for adoptive T-cell therapy. Oncoimmunology 9: 1682381, 2019.

7. Lee AK and Potts PR: A comprehensive guide to the MAGE family of ubiquitin ligases. J Mol Biol 429: 1114-1142, 2017.

8. Liu S, Zhao Y, Xu Y, Sang M, Zhao R, Gu L and Shan B: The clinical significance of methylation of MAGE-A1 and-A3 promoters and expression of DNA methyltransferase in patients with laryngeal squamous cell carcinoma. Am J Otolaryngol 41: 102318, 2020.

9. De Donato M, Peters SO, Hussain T, Rodulfo H, Thomas BN, Babar ME and Imumorin IG: Molecular evolution of type II MAGE genes from ancestral MAGED2 gene and their phylogenetic resolution of basal mammalian clades. Mamm Genome 28: 443-454, 2017.

10. Barker PA and Salehi A: The MAGE proteins: Emerging roles in cell cycle progression, apoptosis, and neurogenetic disease. J Neurosci Res 67: 705-712, 2002.

11. Doyle JM, Gao J, Wang J, Yang M and Potts PR: MAGE-RING protein complexes comprise a family of E3 ubiquitin ligases. Mol Cell 39: 963-974, 2010.

12. Feng Y, Gao J and Yang M: When MAGE meets RING: Insights into biological functions of MAGE proteins. Protein Cell 2: 7-12, 2011.

13. Pineda CT, Ramanathan S, Fon Tacer K, Weon JL, Potts MB, Ou YH, White MA and Potts PR: Degradation of AMPK by a cancer-specific ubiquitin ligase. Cell 160: 715-728, 2015.

14. Mao Y, Fan W, Hu H, Zhang L, Michel J, Wu Y, Wang J, Jia L, Tang X, Xu L, et al: MAGE-A1 in lung adenocarcinoma as a promising target of chimeric antigen receptor T cells. J Hematol Oncol 12: 106, 2019.

15. Kerkar SP, Wang ZF, Lasota J, Park T, Patel K, Groh E, Rosenberg SA and Miettinen MM: MAGE-a is more highly expressed than NY-ESO-1 in a systematic immunohistochemical analysis of 3668 cases. J Immunother 39: 181-187, 2016.

16. Hao YH, Doyle JM, Ramanathan S, Gomez TS, Jia D, Xu M, Chen ZJ, Billadeau DD, Rosen MK and Potts PR: Regulation of WASH-dependent actin polymerization and protein trafficking by ubiquitination. Cell 152: 1051-1064, 2013.

17. Taniura H, Kobayashi M and Yoshikawa K: Functional domains of necdin for protein-protein interaction, nuclear matrix targeting, and cell growth suppression. J Cell Biochem 94: 804-815, 2005.

18. Chen YC, Hsu WL, Chiu CY, Liao JW, Chang CC and Chang SC: Expression of MAGE-A restricted to testis and ovary or to various cancers in dogs. Vet Immunol Immunopathol 153: 26-34, 2013.

19. Fon Tacer K, Montoya MC, Oatley MJ, Lord T, Oatley JM, Klein J, Ravichandran R, Tillman H, Kim M, Connelly JP, et al: MAGE cancer-testis antigens protect the mammalian germline under environmental stress. Sci Adv 5: eaav4832, 2019. 
20. Mouri A, Sasaki A, Watanabe K, Sogawa C, Kitayama S, Mamiya T, Miyamoto Y, Yamada K, Noda Y and Nabeshima T: MAGE-D1 regulates expression of depression-like behavior through serotonin transporter ubiquitylation. J Neurosci 32: 4562-4580, 2012.

21. Saenko V, Rogounovitch T, Shimizu-Yoshida Y, Abrosimov A, Lushnikov E, Roumiantsev P, Matsumoto N, Nakashima M, Meirmanov S, Ohtsuru A, et al: Novel tumorigenic rearrangement, delta $\mathrm{rfp} / \mathrm{ret}$, in a papillary thyroid carcinoma from externally irradiated patient. Mutat Res 527: 81-90, 2003.

22. Cai X, Srivastava S, Sun Y, Li Z, Wu H, Zuvela-Jelaska L, Li J, Salamon RS, Backer JM and Skolnik EY: Tripartite motif containing protein 27 negatively regulates CD4 T cells by ubiquitinating and inhibiting the class II PI3K-C2 $\beta$. Proc Natl Acad Sci USA 108: 20072-20077, 2011.

23. van den Elsen GA, Tobben L, Ahmed AI, Verkes RJ, Kramers C, Marijnissen RM, Olde Rikkert MG and van der Marck MA: Effects of tetrahydrocannabinol on balance and gait in patients with dementia: A randomised controlled crossover trial. J Psychopharmacol 31: 184-191, 2017.

24. Carias KV, Zoeteman M, Seewald A, Sanderson MR, Bischof JM and Wevrick R: A MAGEL2-deubiquitinase complex modulates the ubiquitination of circadian rhythm protein CRY1. PLoS One 15: e0230874, 2020

25. Faktor J, Pjechová M, Hernychová L and Vojtěšek B: Protein ubiquitination research in oncology. Klin Onkol 32 (Suppl 3): S56-S64, 2019

26. Swatek KN and Komander D: Ubiquitin modifications. Cell Res 26: 399-422, 2016.

27. Shaid $\mathrm{S}$, Brandts $\mathrm{CH}$, Serve $\mathrm{H}$ and Dikic I: Ubiquitination and selective autophagy. Cell Death Differ 20: 21-30, 2013.

28. Mattiroli $\mathrm{F}$ and Penengo L: Histone ubiquitination: An integrative signaling platform in genome stability. Trends Genet 37 : 566-581, 2021.

29. Krützfeldt M, Ellis M, Weekes DB, Bull JJ, Eilers M, Vivanco MD, Sellers WR and Mittnacht S: Selective ablation of retinoblastoma protein function by the RET finger protein. Mol Cell 18: 213-224, 2005

30. Zoumpoulidou G, Broceño C, Li H, Bird D, Thomas G and Mittnacht S: Role of the tripartite motif protein 27 in cancer development. J Natl Cancer Inst 104: 941-952, 2012.

31. Scott KL, Kabbarah O, Liang MC, Ivanova E, Anagnostou V, Wu J, Dhakal S, Wu M, Chen S, Feinberg T, et al: GOLPH3 modulates mTOR signalling and rapamycin sensitivity in cancer. Nature 459: 1085-1090, 2009.

32. Kozakova L, Vondrova L, Stejskal K, Charalabous P, Kolesar P, Lehmann AR, Uldrijan S, Sanderson CM, Zdrahal Z and Palecek JJ: The melanoma-associated antigen 1 (MAGEA1) protein stimulates the E3 ubiquitin-ligase activity of TRIM31 within a TRIM31-MAGEA1-NSE4 complex. Cell Cycle 14: 920-930, 2015

33. Zech T, Calaminus SD, Caswell P, Spence HJ, Carnell M, Insall RH, Norman J and Machesky LM: The Arp2/3 activator WASH regulates $\alpha 5 \beta 1$-integrin-mediated invasive migration. J Cell Sci 124: 3753-3759, 2011.

34. Small SA: Retromer sorting: A pathogenic pathway in late-onset Alzheimer disease. Arch Neurol 65: 323-328, 2008.

35. Blalock EM, Geddes JW, Chen KC, Porter NM, Markesbery WR and Landfield PW: Incipient Alzheimer's disease: Microarray correlation analyses reveal major transcriptional and tumor suppressor responses. Proc Natl Acad Sci USA 101: 2173-2178, 2004.

36. Osterlund $\mathrm{C}$, Töhönen V, Forslund $\mathrm{KO}$ and Nordqvist $\mathrm{K}$ : Mage-b4, a novel melanoma antigen (MAGE) gene specifically expressed during germ cell differentiation. Cancer Res 60: 1054-1061, 2000.

37. Gjerstorff MF, Harkness L, Kassem M, Frandsen U, Nielsen O, Lutterodt M, Møllgård K and Ditzel HJ: Distinct GAGE and MAGE-A expression during early human development indicate specific roles in lineage differentiation. Hum Reprod 23 2194-2201, 2008.

38. Hao YH, Fountain MD Jr, Fon Tacer K, Xia F, Bi W, Kang SH, Patel A, Rosenfeld JA, Le Caignec C, Isidor B, et al: USP7 acts as a molecular rheostat to promote WASH-dependent endosoma protein recycling and is mutated in a human neurodevelopmental disorder. Mol Cell 59: 956-969, 2015.

39. Wang J, Teng JL, Zhao D, Ge P, Li B, Woo PC and Liu CH: The ubiquitin ligase TRIM27 functions as a host restriction factor antagonized by mycobacterium tuberculosis PtpA during mycobacterial infection. Sci Rep 6: 34827, 2016.
40. Wang D, Wang J, Ding N, Li Y, Yang Y, Fang X and Zhao H MAGE-A1 promotes melanoma proliferation and migration through C-JUN activation. Biochem Biophys Res Commun 473: 959-965, 2016.

41. Sang M, Gu L, Yin D, Liu F, Lian Y, Zhang X, Liu S, Huang W, Wu Y and Shan B: MAGE-A family expression is correlated with poor survival of patients with lung adenocarcinoma: A retrospective clinical study based on tissue microarray. J Clin Pathol 70: 533-540, 2017.

42. Sang M, Gu L, Liu F, Lian Y, Yin D, Fan X, Ding C, Huang W, Liu S and Shan B: Prognostic significance of MAGE-A11 in esophageal squamous cell carcinoma and identification of related genes based on DNA microarray. Arch Med Res 47: 151-161, 2016.

43. Tacer KF and Potts PR: Cellular and disease functions of the Prader-Willi syndrome gene MAGEL2. Biochem J 474: 2177-2190, 2017.

44. Xiao TZ, Bhatia N, Urrutia R, Lomberk GA, Simpson A and Longley BJ: MAGE I transcription factors regulate KAP1 and KRAB domain zinc finger transcription factor mediated gene repression. PLoS One 6: e23747, 2011

45. Yang G, Fu Y, Lu X, Wang M, Dong H and Li Q: miR-34a regulates the chemosensitivity of retinoblastoma cells via modulation of MAGE-A/p53 signaling. Int J Oncol 54: 177-187, 2019.

46. Borden KL: RING domains: Master builders of molecular scaffolds? J Mol Biol 295: 1103-1112, 2000.

47. Jackson PK, Eldridge AG, Freed E, Furstenthal L, Hsu JY, Kaiser BK and Reimann JD: The lore of the RINGs: Substrate recognition and catalysis by ubiquitin ligases. Trends Cell Biol 10: 429-439, 2000

48. Lupo A, Cesaro E, Montano G, Zurlo D, Izzo P and Costanzo P: KRAB-zinc finger proteins: A repressor family displaying multiple biological functions. Curr Genomics 14: 268-278, 2013.

49. Santos J and Gil J: TRIM28/KAP1 regulates senescence. Immunol Lett 162: 281-289, 2014.

50. Lian Y, Meng L, Ding P and Sang M: Epigenetic regulation of MAGE family in human cancer progression-DNA methylation, histone modification, and non-coding RNAs. Clin Epigenetics 10: $115,2018$.

51. Ladelfa MF, Peche LY, Toledo MF, Laiseca JE, Schneider C and Monte M: Tumor-specific MAGE proteins as regulators of p53 function. Cancer Lett 325: 11-17, 2012.

52. Gure AO, Chua R, Williamson B, Gonen M, Ferrera CA, Gnjatic S, Ritter G, Simpson AJ, Chen YT, Old LJ and Altorki NK: Cancer-testis genes are coordinately expressed and are markers of poor outcome in non-small cell lung cancer. Clin Cancer Res 11: 8055-8062, 2005.

53. Zhang S, Zhai X, Wang G, Feng J, Zhu H, Xu L, Mao G and Huang J: High expression of MAGE-A9 in tumor and stromal cells of non-small cell lung cancer was correlated with patient poor survival. Int J Clin Exp Pathol 8: 541-550, 2015.

54. Carling D: AMPK signalling in health and disease. Curr Opin Cell Biol 45: 31-37, 2017.

55. Yang F, Zhou X, Miao X, Zhang T, Hang X, Tie R, Liu N, Tian F, Wang F and Yuan J: MAGEC2, an epithelial-mesenchymal transition inducer, is associated with breast cancer metastasis. Breast Cancer Res Treat 145: 23-32, 2014.

56. Daudi S, Eng KH, Mhawech-Fauceglia P, Morrison C, Miliotto A, Beck A, Matsuzaki J, Tsuji T, Groman A, Gnjatic S, et al: Expression and immune responses to MAGE antigens predict survival in epithelial ovarian cancer. PLoS One 9: e104099, 2014

57. Wischnewski F, Friese O, Pantel K and Schwarzenbach $\mathrm{H}$ Methyl-CpG binding domain proteins and their involvement in the regulation of the MAGE-A1, MAGE-A2, MAGE-A3, and MAGE-A12 gene promoters. Mol Cancer Res 5: 749-759, 2007.

58. Xu Y, Wang $\mathrm{C}$, Zhang Y, Jia L and Huang J: Overexpression of MAGE-A9 is predictive of poor prognosis in epithelial ovarian cancer. Sci Rep 5: 12104, 2015

59. Jeon $\mathrm{CH}, \mathrm{Kim} \mathrm{IH}$ and Chae HD: Prognostic value of genetic detection using CEA and MAGE in peritoneal washes with gastric carcinoma after curative resection: Result of a 3-year follow-up. Medicine (Baltimore) 93: e83, 2014

60. Gu X, Fu M, Ge Z, Zhan F, Ding Y, Ni H, Zhang W, Zhu Y, Tang X, Xiong L, et al: High expression of MAGE-A9 correlates with unfavorable survival in hepatocellular carcinoma. Sci Rep 4: 6625, 2014

61. Hardie DG, Ross FA and Hawley SA: AMPK: A nutrient and energy sensor that maintains energy homeostasis. Nat Rev Mol Cell Biol 13: 251-262, 2012

62. White E: Deconvoluting the context-dependent role for autophagy in cancer. Nat Rev Cancer 12: 401-410, 2012 
63. Karpf AR, Bai S, James SR, Mohler JL and Wilson EM: Increased expression of androgen receptor coregulator MAGE-11 in prostate cancer by DNA hypomethylation and cyclic AMP. Mol Cancer Res 7: 523-535, 2009

64. Kondo T, Zhu X, Asa SL and Ezzat S: The cancer/testis antigen melanoma-associated antigen-A3/A6 is a novel target of fibroblast growth factor receptor 2-IIIb through histone $\mathrm{H} 3$ modifications in thyroid cancer. Clin Cancer Res 13: 4713-4720, 2007.

65. Yang B, Wu J, Maddodi N, Ma Y, Setaluri V and Longley BJ: Epigenetic control of MAGE gene expression by the KIT tyrosine kinase. J Invest Dermatol 127: 2123-2128, 2007.

66. Kouhara H, Hadari YR, Spivak-Kroizman T, Schilling J, Bar-Sagi D, Lax I and Schlessinger J: A lipid-anchored Grb2-binding protein that links FGF-receptor activation to the Ras/MAPK signaling pathway. Cell 89: 693-702, 1997.

67. Weber J, Salgaller M, Samid D, Johnson B, Herlyn M, Lassam N Treisman J and Rosenberg SA: Expression of the MAGE-1 tumor antigen is up-regulated by the demethylating agent 5-aza-2'-deoxycytidine. Cancer Res 54: 1766-1771, 1994.

68. Vatolin S, Abdullaev Z, Pack SD, Flanagan PT, Custer M, Loukinov DI, Pugacheva E, Hong JA, Morse H III, Schrump DS, et al: Conditional expression of the CTCF-paralogous transcriptional factor BORIS in normal cells results in demethylation and derepression of MAGE-A1 and reactivation of other cancer-testis genes. Cancer Res 65: 7751-7762, 2005.

69. Schwarzenbach H, Eichelser C, Steinbach B, Tadewaldt J, Pantel K, Lobanenkov V and Loukinov D: Differential regulation of MAGE-A1 promoter activity by BORIS and Sp1, both interacting with the TATA binding protein. BMC Cancer 14: 796, 2014

70. Colemon A, Harris TM and Ramanathan S: DNA hypomethylation drives changes in MAGE-A gene expression resulting in alteration of proliferative status of cells. Genes Environ 42: 24, 2020.

71. Gu L, Sang M, Li J, Liu F, Wu Y, Liu S, Wang P and Shan B: Expression and prognostic significance of MAGE-A11 and transcription factors (SP1,TFCP2 and ZEB1) in ESCC tissues. Pathol Res Pract 215: 152446, 2019.

72. Chen A, Santana AL, Doudican N, Roudiani N, Laursen K, Therrien JP, Lee J, Felsen D and Carucci JA: MAGE-A3 is a prognostic biomarker for poor clinical outcome in cutaneous squamous cell carcinoma with perineural invasion via modulation of cell proliferation. PLoS One 15: e0241551, 2020.

73. Bai S, He B and Wilson EM: Melanoma antigen gene protein MAGE-11 regulates androgen receptor function by modulating the interdomain interaction. Mol Cell Biol 25: 1238-1257, 2005.

74. Li XF, Ren P, Shen WZ, Jin X and Zhang J: The expression, modulation and use of cancer-testis antigens as potential biomarkers for cancer immunotherapy. Am J Transl Res 12: 7002-7019, 2020.

75. Bai S and Wilson EM: Epidermal-growth-factor-dependent phosphorylation and ubiquitinylation of MAGE-11 regulates its interaction with the androgen receptor. Mol Cell Biol 28: 1947-1963, 2008

76. Aprelikova O, Pandolfi S, Tackett S, Ferreira M, Salnikow K, Ward Y, Risinger JI, Barrett JC and Niederhuber J: Melanoma antigen-11 inhibits the hypoxia-inducible factor prolyl hydroxylase 2 and activates hypoxic response. Cancer Res 69: 616-624, 2009.
77. James SR, Cedeno CD, Sharma A, Zhang W, Mohler JL, Odunsi K, Wilson EM and Karpf AR: DNA methylation and nucleosome occupancy regulate the cancer germline antigen gene MAGEA11. Epigenetics 8: 849-863, 2013.

78. Krüger S, Ola V, Feller AC, Fischer D and Friedrich M: Expression of cancer-testis antigen CT7 (MAGE-C1) in breast cancer: An immunohistochemical study with emphasis on prognostic utility. Pathol Oncol Res 13: 91-96, 2007.

79. Bai S, Grossman G, Yuan L, Lessey BA, French FS, Young SL and Wilson EM: Hormone control and expression of androgen receptor coregulator MAGE-11 in human endometrium during the window of receptivity to embryo implantation. Mol Hum Reprod 14: 107-116, 2008

80. Wilson EM: Androgen receptor molecular biology and potential targets in prostate cancer. Ther Adv Urol 2: 105-117, 2010.

81. Askew EB, Bai S, Hnat AT, Minges JT and Wilson EM: Melanoma antigen gene protein-A11 (MAGE-11) F-box links the androgen receptor NH2-terminal transactivation domain to p160 coactivators. J Biol Chem 284: 34793-34808, 2009.

82. Su S, Minges JT, Grossman G, Blackwelder AJ, Mohler JL and Wilson EM: Proto-oncogene activity of melanoma antigen-A11 (MAGE-A11) regulates retinoblastoma-related p107 and E2F1 proteins. J Biol Chem 288: 24809-24824, 2013.

83. Yin B, Zeng Y, Liu G, Wang X, Wang P and Song Y: MAGE-A3 is highly expressed in a cancer stem cell-like side population of bladder cancer cells. Int J Clin Exp Pathol 7: 2934-2941, 2014.

84. Wienand K and Shires K: The use of MAGE C1 and flow cytometry to determine the malignant cell type in multiple myeloma. PLoS One 10: e0120734, 2015.

85. Atanackovic D, Luetkens T, Hildebrandt Y, Arfsten J, Bartels K, Horn C, Stahl T, Cao Y, Zander AR, Bokemeyer C and Kröger N: Longitudinal analysis and prognostic effect of cancer-testis antigen expression in multiple myeloma. Clin Cancer Res 15: 1343-1352, 2009.

86. Chen X, Wang L, Liu J, Huang L, Yang L, Gao Q, Shi X, Li J, Li F, Zhang Z, et al: Expression and prognostic relevance of MAGE-A3 and MAGE-C2 in non-small cell lung cancer. Oncol Lett 13: 1609-1618, 2017.

87. Yang B, O'Herrin SM, Wu J, Reagan-Shaw S, Ma Y, Bhat KM, Gravekamp C, Setaluri V, Peters N, Hoffmann FM, et al: MAGE-A, mMage-b, and MAGE-C proteins form complexes with KAP1 and suppress p53-dependent apoptosis in MAGE-positive cell lines. Cancer Res 67: 9954-9962, 2007.

This work is licensed under a Creative Commons Attribution-NonCommercial-NoDerivatives 4.0 International (CC BY-NC-ND 4.0) License. 